\title{
A Social Interactional Model of Bereavement Narrative Disclosure
}

\author{
Jenna L. Baddeley \\ University of Texas at Austin
}

\author{
Jefferson A. Singer \\ Connecticut College
}

\begin{abstract}
According to recent bereavement research, disclosing the narrative of one's loss does not per se promote emotional recovery. At the same time, social, personality, and developmental research suggests that telling personal stories is an important means of building identity and relationships throughout adulthood. Drawing on this literature, this review illustrates how bereavement narrative disclosure may be instrumental in addressing psychosocial challenges associated with bereavement (e.g., relationship formation, identity reconstruction, and meaning making). Multiple individual and social factors may affect how successful bereavement narrative disclosure is these challenges. Applying a social interactional model of memory telling, this review examines the influence of the relationship of narrator and listener, their personality characteristics, the content and structure of the narrative, the type of loss, and the time since the loss in facilitating or disrupting the putative goals of bereavement narrative disclosure. The utility of this model for clinicians working with bereaved individuals is also explored.
\end{abstract}

Keywords: bereavement, grief, narrative memory, disclosure

I lost the only man I ever wanted to spend the rest of my life with. I just knew we would marry and have a future together. Unfortunately fate had other plans. He was killed by a drunk driver on January 1st. What a way to start the New Year! Now the love of my life is gone and my son no longer has a father. After his death, my son had to have therapy (he was only 4 years old) to cope. He is doing better but still misses him terribly. I on the other hand miss him even more. I have not been in another relationship since being with him and I do not foresee that happening.

—Anonymous Participant

Why do we share such painful stories with each other? Are we simply expressing our pain in the hope that we might feel better? Or are we hoping that a dialogue with another person about our loss might bring insight that will make the tragedy more comprehensible or at least allow us to extract some meaning from our loss? Maybe we are seeking to be known by - and to build intimacy with - another. Aside from our reasons for telling the story, how does the way we tell it - the themes and structure of the narrative itself-affect the way that others respond to us, the storytellers? Ultimately, what benefits and costs might sharing the story have for narrator and listener?

If one explores the vast literature on grief or surfs the Internet for websites devoted to bereavement and coping with loss, a persistent theme is that individuals need to experience and express their pain to recover from their loss (Attig, 1996; Gersie, 1991; Kubler-Ross \& Kessler, 2005; Olsen, 2007; Parkes, 2006; Worden, 2002). For example, the nationally known "grief expert," Alan Wolfelt (1998), director of the Center for Loss and Transitions in Fort Collins, Colorado, stated emphatically on the back cover of his book, Healing Your Grieving Heart: 100 Practical Ideas,

Jenna L. Baddeley, Department of Psychology, University of Texas at Austin; Jefferson A. Singer, Department of Psychology, Connecticut College.

Correspondence concerning this article should be addressed to Jenna L. Baddeley, Department of Psychology, University of Texas at Austin, 1 University Station A8000, Austin, TX 78712. E-mail: jenna@mail .utexas.edu
"When someone loved dies, we must express our grief if we are to heal." LaRita Archibald (n.d.), founder of Heartbeat, a network of groups for individuals who have lost a loved one to suicide, offers the following advice to the bereaved: "Talk! Talk! Talk! Speak of your pain and loss for as long and as often as you need to speak of it."

In contrast, Bonanno and his colleagues (2001; Bonanno \& Keltner, 1997) and Stroebe and Stroebe and their colleagues (M. S. Stroebe, Schut, \& Stroebe, 2005; M. S. Stroebe \& Stroebe, 1991; M. S. Stroebe, Stroebe, Schut, Zech, \& van den Bout, 2002) offered a more nuanced view of bereavement, supported by careful empirical studies, both cross-sectional and longitudinal. They argued that the expression of grief and the active "working through" of one's loss and the negative emotions associated with it are neither necessary nor a sign of health for all bereaved individuals (see also Wortman \& Boerner, 2007). Bereaved people who express high levels of positive emotion and who show a pattern of emotional avoidance (low levels of distress relative to higher levels of autonomic arousal when talking about the deceased spouse) in interviews 6 months following the loss of a spouse have less grief-related distress and disruption at 14 and 25 months following loss (Bonanno \& Keltner, 1997; Bonanno, Keltner, Holen, \& Horowitz, 1995; Bonanno, Znoj, Siddique \& Horowitz, 1999). In a review of the evidence on the benefits of loss disclosure, including evidence from their own large longitudinal study (M. S. Stroebe et al., 2002), Stroebe, Schut, \& Stroebe (2005) concluded that neither induced nor naturally occurring disclosure is associated with better adjustment either concurrently or at follow-up for up to 2 years later.

The goal of this review is to provide a new perspective on the disclosure of loss that offers a different way to look at the potential outcomes and relative merits of telling one's story of loss. Drawing on an emerging literature that links developmental, social, and personality psychology, we argue that the telling of a loss story is one subtype of an important class of social interaction- "narrative disclosure" or "memory telling" (Alea \& Bluck, 2003; McLean, Pasupathi, \& Pals, 2007; Pasupathi, 2001, 2003; Thorne \& 
McLean, 2003). From this perspective, the expression of a personal narrative to a listener is a powerful way in which we build our identities, forge interpersonal connections, and sustain a sense of purpose and meaning. Further, narrative disclosures go beyond individual purposes and can be viewed from a contextual point of view. They play a role in social exchanges and rituals that define the nature of intimacy, friendship, work relations, and community membership.

Listeners heavily affect the content and nature of the memory narrative being disclosed: Attentive listeners enhance both story quality and long-term recall of narratives of remembered events (Pasupathi, Stallworth, \& Murdoch, 1998). Depending on their behavior, listeners can facilitate or disrupt the work of identity building and verification that tellers may be doing with their stories (Pasupathi \& Rich, 2005). Whether one takes an intrapersonal, interpersonal, or societal perspective on narrative disclosure, the story of telling one's story of loss is a more complex and nuanced tale than the rhetoric in the popular media about grief and loss typically conveys. Telling another person about an intimate loss is a sociocultural act that cannot be divorced from the goals of the interaction, the personality dynamics of each member of the dyad, and the social roles that both participants inhabit.

In a helpful synthesis of memory-telling research, Alea and Bluck (2003) proposed a conceptual model that suggests how the social functions of the telling of an autobiographical memory are affected by the characteristics of the autobiographical memory that is told, and also by the characteristics of the speaker, the listener, their relationship, and the interaction between them (see Figure 1). The social functions served by memory telling include establishing rapport, building intimacy, and sharing life lessons.

This general model provides a framework that can be adapted to fit various types of autobiographical memory disclosure. In this article we use Alea and Bluck's (2003) model to derive a specific model tailored to the special case of disclosing autobiographical memories of bereavement. The new model contains variables that are particularly salient for bereaved individuals (time since loss and type of loss) as well as adjustment challenges that are likely to figure uniquely for bereaved individuals (e.g., reworking bonds with the deceased). As mentioned earlier, Alea and Bluck's model applied specifically to the social functions of autobiographical memory telling. In the bereavement-specific model, we acknowledge these social functions, but also include self-oriented functions that encompass emotional recovery and identity reconstruction. Using the special case of bereavement, we argue that these selffunctions also belong in a social interactional model of memory telling because they are powerfully served and influenced by disclosure of narrative memories in social contexts.

In the next section of this review, we discuss the major adjustment challenges that bereaved individuals face, while highlighting the potential benefits and pitfalls of telling stories of loss with regard to these challenges. To clarify the conditions and influences that might make loss disclosure more or less effective, we then present our new social interactional model of bereavement narrative disclosure. The model illustrates how theoretical and empirical work on narrative memory, personality, social cognition, and discourse processes, including recent research findings from our laboratory, helps to shed light on optimal conditions for telling stories of loss. The discussion concludes with the implications of our model for future research on memory telling in general as well as an examination of the applicability of the model in the treatment of bereaved individuals. Clinicians should find this model useful in assisting clients to maximize the benefits of telling loss stories in their everyday lives in the service of better adjustment and stronger relationships.

\section{Adjustment Challenges in Response to Bereavement}

To develop a social interactional model of bereavement narrative disclosure, we need to consider the particular challenges that confront individuals who have suffered significant losses in their lives. These challenges include: (a) coping with the emotional pain of the loss (Bonanno \& Kaltman, 1999; Conant, 1996; NolenHoeksema, 2001; M. S. Stroebe \& Schut, 2001), (b) incorporating the loss into a changed identity (Conant, 1996; Harvey, Orbuch, Weber, Merbach, \& Alt, 1992; Parkes, 2006; M. S. Stroebe \& Schut, 2001) and finding new goals and purposes for one's life (Conant, 1996; M. S. Stroebe \& Schut, 2001), (c) continuing one's bond with the deceased (Klass, 1996; Rubin \& Malkinson, 2001;

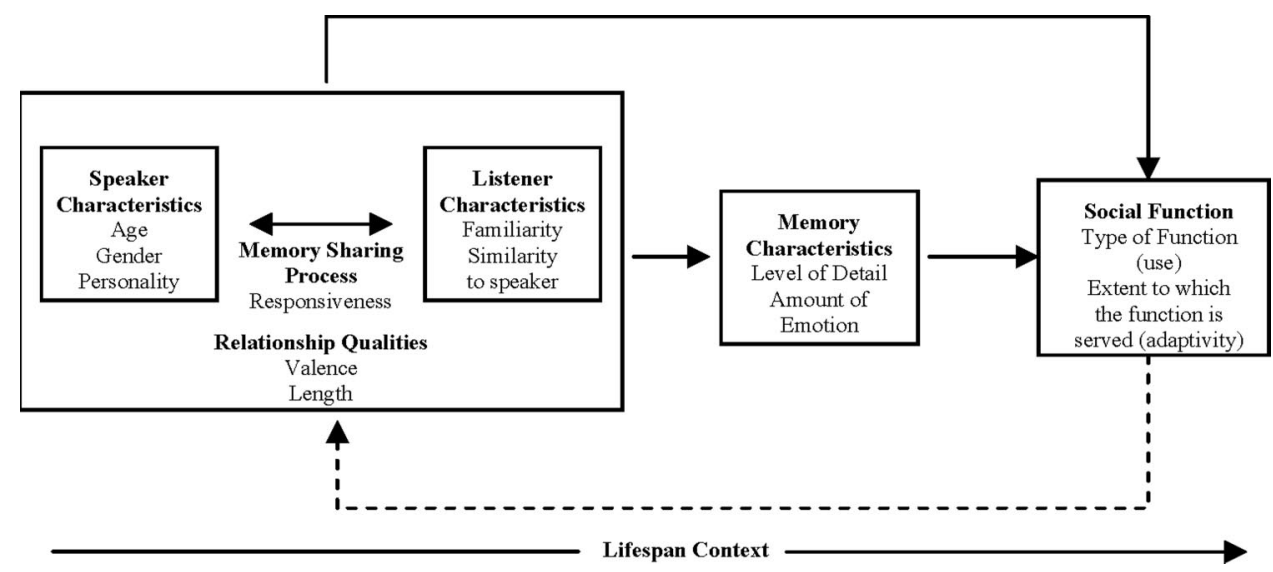

Figure 1. Conceptual model of the social functions of autobiographical memory. Reprinted with permission from "Why are you telling me that? A conceptual model of the social function of autobiographical memory," by N. Alea and S. Bluck, 2003, Memory, 11, pp. 165-178. Copyright 2003 by Taylor \& Francis. 
Silverman, Nickman \& Worden, 1992; Walter, 1996), (d) strengthening one's relationships with the living by developing new intimate bonds and maintaining old ones (Freud, 1917/1957; Klass, 1996; Rubin \& Malkinson, 2001), and (e) sharing life lessons learned from the loss (Harvey et al., 1992). The first two of these tasks or challenges (emotional recovery and identity, meaning, and goal reconstruction) can be considered intrapersonal challenges and the last three (continuing the bond with deceased, developing or maintaining bonds with the living, and sharing of lessons learned) can be considered interpersonal challenges (see Figure 2).

\section{Intrapersonal Challenges}

Emotional recovery. Obviously, negative emotions such as sadness and loneliness are virtually universal among the recently bereaved (Burnett, Middleton, Raphael, \& Martinek, 1997); however, there are individual differences in the intensity and duration of distress (e.g., bereaved parents report higher levels of distress than bereaved adult children; Burnett et al., 1997). There is some evidence that, soon after bereavement, more distress leads to more disclosure (M. S. Stroebe et al., 2002). This finding is consistent with the finding of that the more intense the emotion, the more frequently it is likely to be shared (Rime, Mesquita, et al., 1991). The sharing may be motivated by a desire to feel better and a belief that sharing will help. Indeed, research has documented that many laypeople endorse a belief that telling the story of the loss and expressing one's thoughts and feelings about it can help one feel better about it (Dyregrov, 2003-2004; Zech, Rime, \& Pennebaker, 2007).

The usefulness of disclosing one's thoughts, feelings, and personal stories about bereavement as a means of improving healthy adjustment and well-being remains a controversial topic in the literature (for a review, see W. Stroebe, Schut, \& Stroebe, 2005). The idea that grief work is a necessary process in healthy adaptation to loss is still widely accepted, and along with it comes the idea that talking about one's loss facilitates emotional recovery (e.g., Harvey et al., 1992). However, empirical evidence suggests that such disclosure is not, per se, helpful (Bonanno, 2001; M. S. Stroebe et al., 2002). These studies have found that the frequency of bereavement disclosure is not related to adjustment (M. S. Stroebe et al., 2002) and that this does not vary by whether the loss was unexpected or expected (M. S. Stroebe et al., 2002). However, disclosures that include genuine positive emotion are prospectively associated with reduced distress (Keltner \& Bonanno, 1997).

In addition, there has been some theoretical consideration regarding the effects of discloser attachment style on the benefits of disclosure (M. S. Stroebe et al., 2006). For example, anxious/ preoccupied individuals probably disclose too indiscriminately and in a ruminative style, which may lead to these disclosures having negative emotional impact. Securely attached individuals may disclose more appropriately in everyday life, which should allow

Intrapersonal Challenges
\begin{tabular}{|l|l|l|l|l|}
\hline $\begin{array}{l}\text { Emotional } \\
\text { recovery }\end{array}$ & $\begin{array}{l}\text { Identity, } \\
\text { meaning, } \\
\text { goals }\end{array}$ & $\begin{array}{l}\text { Interpersonal Challenges } \\
\text { bond } \\
\text { with } \\
\text { deceased }\end{array}$ & $\begin{array}{l}\text { Bonds } \\
\text { with the } \\
\text { living }\end{array}$ & $\begin{array}{l}\text { Sharing } \\
\text { lessons } \\
\text { with } \\
\text { others }\end{array}$ \\
\hline
\end{tabular}

Figure 2. The psychosocial tasks/challenges of bereavement. them to avoid negative reactions from unwilling listeners. However, neither the role of attachment style nor the role of any other personality-type characteristics in influencing the adaptiveness of disclosure has been empirically tested. In addition, no published studies have systematically examined other social interactional factors, such as the relational context in which the disclosure takes place, the effect of the behavior and personality of the listener who is hearing the disclosure, or the impact of the amount of time that has passed since the loss, in determining whether the disclosure contributes to better adjustment and effective emotional recovery.

Identity, meaning, and goal reconstruction. One of the challenges of bereavement is reconstituting one's identity. Identity is in part relational; we define our loved ones as part of ourselves (James, 1890/1950), and we also define ourselves in terms of the social roles that we occupy and the daily routines that shape our lives. Bereaved individuals are faced not only with the loss of a loved one, but also with relinquishing old social roles (e.g., spouse) and adopting new ones (e.g., widow/widower; Parkes, 2006). Bereavement may entail a significant reevaluation of one's life goals, particularly when one's goals and plans were bound up with the ongoing life of the deceased. Bereavement challenges other aspects of identity, namely the assumptions that we make about how strong or vulnerable, or how blessed or unlucky we are (Janoff-Bulman, 1992; Neimeyer, 2001; Parkes, 2006), all of which are related to basic assumptions about the meaningfulness of the world.

As we mentioned earlier in the paper, the rehearsal and telling of narrative memories is a primary way of developing and revising one's identity. Narrative processing, that is, using the devices of story such as plot, character, theme, and outcome, to organize and explain experience, allows individuals to evaluate an event in terms of its relationship to the evolving life goals that organize behavior, cognition, and affect (Singer \& Blagov, 2004; Singer \& Bluck, 2001). We must emphasize the importance of social sharing — not just rehearsal - of narrative memories in identity development (cf. McLean et al., 2007). Bereavement is the kind of event that especially calls for the revision of identity in social contexts. Bereavement is frequently a shared experience rather than an individual one: The loved one's death has left multiple people bereaved. Insofar as the bereaved talk to each other and share stories about the death, they are likely to be influencing each other's identity revision (Nadeau, 2001). The mere presence of a listener as a witness to one's stated intentions, as well as the listener's reactions and interpretations, can shape the ways that narrators tell their stories and understand the events that are the subject of those stories (Janoff-Bulman, 1992; Pasupathi, 2001). Listeners also introduce their own interpretations of the situation by expressing agreement or disagreement with the teller's perspective, by offering new information, and by empathizing or showing discomfort. These responses will shape the narrative that is told in that conversation and may also influence the teller's basic assumptions about the world. In one study, individuals who had received empathic responses after watching a negative film clip endorsed a greater belief in a just world than individuals who had received unempathic responses (Zech, Rime, \& Nils, 2004). The same effects may emerge in the case of telling bereavement stories.

Listeners' influence is multifaceted, and ranges from passive and subtle to a very active coconstructing influence. The production of future-oriented goals in socially shared bereavement stories 
may be in part a response to social pressures from listeners who display signs of discomfort with loss-oriented narrative content. Listener discomfort may be read as a signal that it is time for the bereaved to "move on." Listeners may also have a more active role in coconstructing the meanings that are created in loss stories. Nadeau's (1998) intensive interview study of bereaved families suggested that families talk to each other extensively about the death and, as a result of these conversations, the different family members adopt a narrative of the loss that bears the stamp of the other family members' interpretations.

As a further example, consider how identity as a bereaved individual is affected by bereavement narrative disclosure in a support group. Individuals in these groups sometimes wear badges with the photographs of their deceased loved ones. To tell your story to this group is to take on a new identity as a member of a particular society and to feel both a new sense of belonging and a sense of separation from others who do not share a similar bereavement narrative. Clearly, the disclosure of this loss story in a support group has very different implications for identity reconfiguration than the telling of the story to a new coworker or a supervisor at work. In the latter work contexts, one may see the revelation as promoting a view of the self as the "wounded or troubled one."

How social interactional variables affect the role of loss disclosure in reconstructing one's postloss identity has not been systematically examined. Are individuals with higher levels of depression or anxiety less likely to find benefit in the disclosure with regard to forging a new sense of self? Would telling an unsympathetic or inattentive listener create a sense of shame and embarrassment that would become part of one's reconfigured identity as a "tainted" or "damaged" person?

\section{Interpersonal Challenges}

Continuing bonds with the deceased. Bereaved individuals are faced with reconfiguring their relationship with the deceased from a relationship with a living person to an incorporation of the memory of the deceased into their ongoing lives (Klass, 1996; Marwit \& Klass, 1996; Walter, 1996). A continuing bond is maintained through remembering good memories of the deceased, sensing the presence of the deceased, retaining possessions from the deceased, and incorporating the deceased's life goals into one's own life. Contrary to Freud's (1917/1957) claim that healthy grieving involves relinquishing bonds with the deceased, researchers recently have contended based on extensive ethnographic research with a support group for bereaved parents, that maintaining bonds with the deceased is a normal response to bereavement (Klass \& Walter, 2001), and indeed, a large-scale, longitudinal study of bereaved spouses documents that the bereaved still think and talk about their partner decades after the death (Carnelley, Wortman, Bolger, \& Burke, 2006).

The issue of continuing bonds is currently controversial in bereavement research in light of recent empirical findings that point to continuing bonds being associated-in Western cultureswith elevated levels of grief symptomatology and poor adjustment. Lalande and Bonanno (2006) showed that maintaining bonds after a loss predicts poorer adjustment more than a year later in American culture, although the reverse was true in Chinese culture. A longitudinal study conducted in the Netherlands found that recall- ing comforting memories of the deceased is predictive of a higher level of grief symptoms 9 months later (Boelen, Stroebe, Schut, \& Zijerveld, 2006). Evidence from a study that measured behaviors reflective of continuing bonds (e.g., having imaginary conversation with the deceased spouse, recalling good memories of the deceased spouse) four times each day showed that "continuing bonds" behavior predicts increased negative mood in people in their first few months after a bereavement, but that this detrimental effect is not present in people whose loss occurred 2 years ago (Field \& Friedrichs, 2004). However, the outcome measures in these empirical studies do not tap what Klass (2001) proposed were the important functions of continuing bonds, including spiritual comfort and a reinforcement of the values that had been shared with the now absent loved one.

The uncertainty about the role of continuing bonds in contributing to healthy adjustment after bereavement makes its inclusion in our model more tentative. However, we include it because we think that regardless of the frequency of reference to continuing bonds (i.e., whether someone thinks or talks about the deceased a lot or a little) the qualitative aspects of their internalized representations of the deceased (i.e., the content and features of narrative memories regarding the loss) are likely to matter for the bereaved person's adjustment.

Memories of the death may figure prominently in accounts of the deceased simply by virtue of the recency effect. The extent to which memories of the death itself (i.e., rather than just memories of the person's life) are used for maintaining a bond with the deceased may depend on the death. If it was a good death (e.g., expected, free of avoidable pain, accompanied by the sense that the dying person had lived a full life) the bereaved may try to actively recruit and share memories of the death circumstances to maintain a positive representation of the deceased. If it was a bad death (e.g., traumatic in some way) it might be avoided when attempting to fondly remember the deceased. Sharing stories about the death, unlike solitary reflection, allows the bereaved to gain social validation for the meaning of the deceased person's life and death (Attig, 1996; Walter, 1996).

Maintaining and developing intimate bonds with the living. The world of intimate relationships is significantly changed after bereavement. Widows tend to spend more time with their siblings and children for about 2 years after the loss of their spouse (Guiaux, van Tilburg, \& van Groenou, 2007). Intensive interview studies with couples (Rosenblatt, 2000) and families (Nadeau, 1998) suggest that, after the loss of a family member, the remaining family members' conversations with each other about the loss facilitate the development of a more or less shared narrative, which in turn maintains family bonds. Family relationships undergo changes after the death of a family member. Parent-child relationships may change in valence and closeness after the death of a coparent; spousal relationships may change after the death of a child. Talking about the loss is likely to play a role in the changing of these relationships.

Talking about the death within the context of close relationships may be, at times, an attempt to find causal attributions. These efforts may be a critical factor in the negotiation of intimacy among family members in the aftermath of the loss. Joint storytelling can interfere with intimacy rather than facilitating it, for example, if it shifts to blaming a family member. One of the 
authors can cite an example from his clinical practice in which after a sibling suicide, the older sister expressed to her brother that if she had known more about the circumstances of the sibling's presuicide distress, she might have been able to help more. The brother, who had been more involved in the deceased sibling's recent struggles, took this statement as a criticism of his efforts and a subsequent rift developed between the surviving siblings.

Stories of bereavement may also be disclosed to acquaintances, strangers, or new friends in an attempt to build intimacy, which entails eliciting social support and empathy. Disclosure is an essential element in the development and maintenance of close relationships (Collins \& Miller, 1994; Laurenceau, Feldman Barrett, \& Pietromonaco, 1998; Reis \& Shaver, 1988). In general, disclosure tends to produce liking in both the discloser and the recipient: People who make intimate disclosures end up being liked more than people who do not, and people tend to like those to whom they have disclosed (Collins \& Miller, 1994). Disclosing stories is an essential way of making oneself known to others (Baddeley \& Singer, 2007).

Aron and colleagues' (Aron, Melinat, Aron \& Vallone, 1997) experimental procedure for generating interpersonal closeness attests to the powerful interpersonal effects of disclosing stories that reveal emotional events and personal values. After $45 \mathrm{~min}$ of answering questions about emotional events and personal values in an experimental setting, people who were perfect strangers before the study reported high levels of interpersonal closeness. Yet in a control condition, in which people were prompted to tell stories and share views with a stranger about less personal, more external topics, stranger pairs felt significantly lower levels of interpersonal closeness than pairs in the other condition (Aron et al., 1997).

The story of a loss (whether recent or distant) is a prime candidate for an intimate disclosure because loss is emotionally charged (Folkman, 2001; Nolen-Hoeksema, 2001) and connected to the bereaved person's thinking about their personal values (e.g., Marwit \& Klass, 1996). As Klass (1996) observed in his studies of a support group for bereaved parents, the very fact that bereavement and loss are so hard to talk about in many social contexts makes the bereaved feel especially bonded with others (such as fellow support group members) with whom they can share their thoughts and feelings about their loss and the deceased loved one. In relation, many bereavement support group participants report feeling close to other members of the group and a majority seek and maintain outside contacts with fellow members (Caserta \& Lund, 1996). More interesting, members' conversations during these outside contacts were generally broad in scope, not limited to discussion of their loss (Caserta \& Lund, 1996), suggesting that, through mutual disclosure of loss, the foundation had been laid for a substantive relationship.

Sharing life lessons. Sharing loss stories can be a generative act in which lessons and sometimes inspiration are passed on to other people (Harvey, Carlson, Huff, \& Green, 2001; Webster, 1993, 2003). Telling the story of a loss can provide lessons about grief, personal recovery, and the sociopolitical impact of the loss. Listeners may learn about what challenges they might expect to face in a similar situation and how they might react to those challenges (Luminet, Bouts, Delie, Manstead, \& Rime, 2000). People who have had losses may find comfort or validation from hearing how another person has reacted to and dealt with a similar loss. Loss stories might also serve to awaken people's attention to important social or political issues. For example, Judy Shepard, whose son Matthew Shepard was beaten to death in a nowinfamous incident of homophobic violence, tells the story of her loss to bear witness to the harm that can result from homophobic attitudes and behavior (Matthew Shepard Foundation, 2007).

Many bereavement support organizations are built on the principle that helping others through providing advice, encouragement, support, and listening is an integral step in one's own healing process. The prominent national network for bereaved parents, the Compassionate Friends, takes the principle of healing through guiding others as the central tenet in their guiding philosophy. The Compassionate Friends' website declares: "The secret of TCF's success is simple: As seasoned grievers reach out to the newly bereaved, energy that has been directed inward begins to flow outward and both are helped to heal" (Compassionate Friends, n.d.). Following the Alcoholics Anonymous model of healing through helping, there has been a burgeoning of Internet support forums based on a similar principle in which people who all have been bereaved can share with and listen to each other.

Despite these examples from recovery and grief support networks, there is no empirical research literature that demonstrates a relationship between the sharing of life wisdom and insight after loss with more effective coping. The lack of systematic study raises several questions about the type of listener who would be most receptive to hearing bereavement narrative disclosures that also contain statements of life lessons and/or meaning making. In addition, are there types of losses that more conducive to the generation of life lessons, and would the time since loss have an influence on individuals' ability to extract meaning from their losses?

\section{Summary}

In the above section, we reviewed the major psychosocial challenges that people face in adapting to loss, while highlighting the role that telling loss stories might play in responding to these challenges. For some of these challenges, (i.e., emotional recovery, developing intimate bonds), findings on the usefulness of narrative disclosure in addressing the challenge are mixed. For other challenges, (e.g., reconstruction of identity), the (co-)construction of narratives is arguably the means through which these tasks are accomplished. Similarly, the social sharing of narratives is a key way of articulating and reinforcing life lessons that emerge from loss. Yet despite the critical relationship of storytelling to these coping tasks, there are very few research studies that have been conducted on these relationships. Research pertaining to the relationship of bereavement narrative telling to continuing bonds and teaching life lessons is especially scant. The findings from these efforts are not conclusive. The psychological literature has only begun to articulate the conditions under which bereavement disclosure might help achieve these adjustment goals — what kinds of disclosures might be effective, for whom disclosing might be effective, and what kinds of listeners would promote disclosure effectiveness. The following model is a first endeavor at providing a more coherent platform for studying the linkage between telling loss stories and effective coping after loss. 


\section{A Social Interactional Model of Bereavement Narrative Disclosure}

Telling one's loss is by definition a social interaction between two people who each bring unique personalities and histories to the exchange. For this reason, the use and usefulness of bereavement story disclosure for addressing each of the five challenges of bereavement can be considered in light of the social interaction conditions based on Alea and Bluck's (2003) model (e.g., teller characteristics, listener characteristics, relationship between listener and teller) with modifications particular to bereavement disclosure (see Figure 3).

The model is intended to apply to the disclosure of autobiographical memories of bereavement in conversations with friends, family, partners, support group members, strangers, coworkers, and other people within the bereaved individual's social environment. Although therapeutic settings are obvious places for the disclosure of autobiographical memories of bereavement, the model is unlikely to apply directly to the disclosure of bereavement narratives in therapy. The telling of autobiographical memories in therapy may effectively serve intrapersonal functions (identity, purpose, and direction), but because the therapeutic relationship is nonreciprocal, telling autobiographical memories in therapy is unlikely to effectively serve interpersonal functions (development of intimacy, passing on life lessons). However, the model does have important therapeutic applications in that therapists can draw on the model to guide their clients toward making effective disclosures (and avoiding harmful disclosures) of their autobiographical memories of loss in their "real life" relationships.

The model is intended to apply to a specific type of story, "bereavement stories" that refer to autobiographical memories, told in narrative form, in which the loss itself is an event in the story. Other kinds of autobiographical memory narratives — stories about the lost loved one that do not refer to the loss event-are also an important kind of memory that can be used by the bereaved for self and social functions. As important as these kinds of memories are, it is beyond the scope of this paper to discuss them.

We now turn to a reexamination of the relationship of telling loss stories to the five bereavement coping challenges in light of the social interactional model of bereavement narrative disclosure. Whenever possible, we highlight the influence or potential influence of the content of the disclosure, the relationship between teller and listener, the personality characteristics of the teller and listener, and the time since loss, all as potential contributors to the outcome of the disclosure interaction. We draw on theoretical work, reviews of empirical studies, and qualitative and quantitative studies in our discussion (see Table 1).

\section{Disclosure Characteristics}

The influence of disclosure characteristics on the intrapersonal challenges addressed by bereavement narratives. Narrative disclosures vary along a range of important dimensions, including features of the narrative itself (e.g., what goals and emotions are expressed in the story, how much detail is included) as well as the way that the story fits into the flow of the conversation. These features of narrative disclosure are important in shaping the overall message and impact of the narrative, and thus, in shaping how it can serve bereavement-related challenges. Although bereaved individuals may report finding benefits and personal growth from the experience, bereavement is by definition a negative event. In the absence of experimental literature that has examined how people

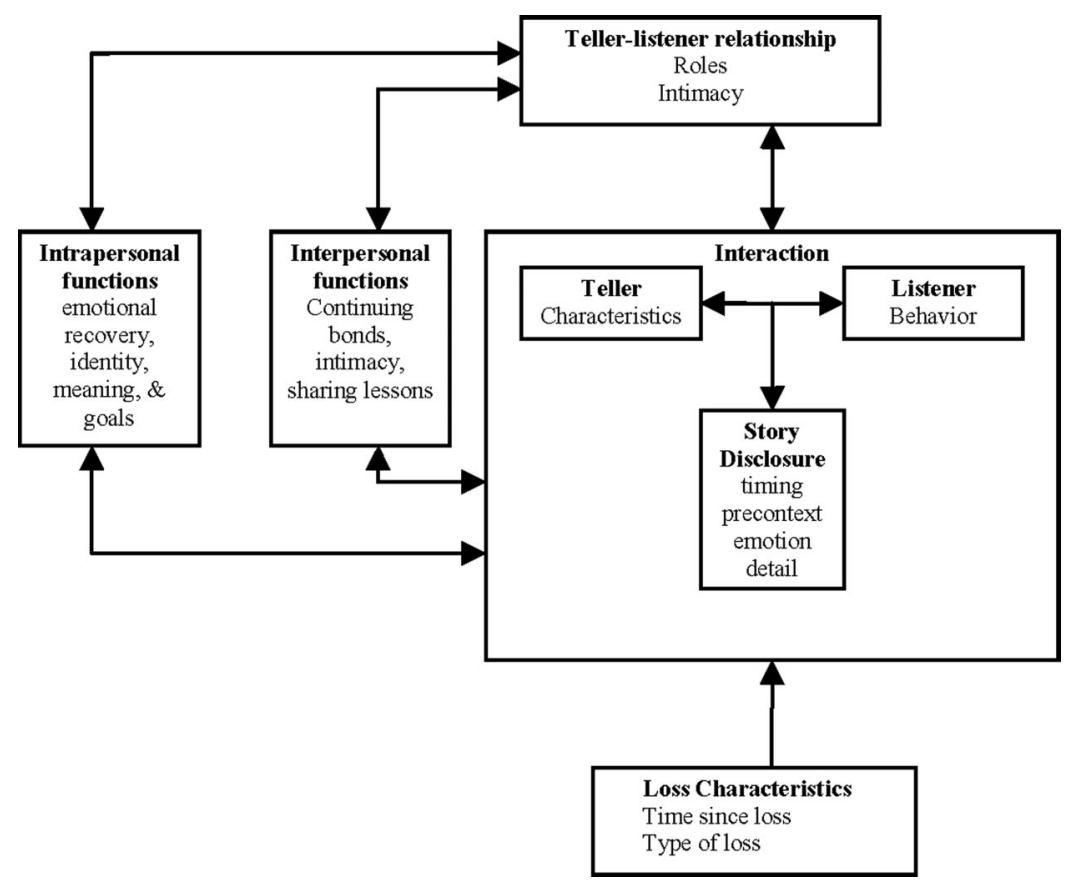

Figure 3. A social interactional model of the functions of bereavement narrative disclosure. Adapted with permission from "Why are you telling me that? A conceptual model of the social function of autobiographical memory," by N. Alea and S. Bluck, 2003, Memory, 11, pp. 165-178. Copyright 2003 by Taylor \& Francis. 
Table 1

Sources of Data

\begin{tabular}{|c|c|c|c|c|c|}
\hline \multicolumn{3}{|c|}{ Intrapersonal challenges } & \multicolumn{3}{|c|}{ Interpersonal challenges } \\
\hline & Identity, purpose & Emotional recovery & Continuing bonds & Intimacy & $\begin{array}{l}\text { Teach life } \\
\text { lessons }\end{array}$ \\
\hline \multirow[t]{5}{*}{$\begin{array}{l}\text { Disclosure } \\
\text { characteristics }\end{array}$} & Pals (2006) Q1 & $\begin{array}{l}\text { Kross, Ayduk, \& Mischel } \\
\text { (2005) Q1 }\end{array}$ & Alea \& Bluck (2007) Q1 & Alea \& Bluck (2003) R & \\
\hline & & Wilson \& Ross (2003) R & & Baddeley \& Singer (2008) Q1 & \\
\hline & & $\begin{array}{l}\text { Clark, Collins, \& Henry } \\
\text { (1994) R }\end{array}$ & & Holtgraves (1990) $\mathrm{T}$ & \\
\hline & & $\begin{array}{l}\text { Blagov \& Singer } \\
\text { (2004) Q1 }\end{array}$ & & Thorne \& McLean (2003) Q2 & \\
\hline & & Williams (1996) R & & & \\
\hline \multirow[t]{6}{*}{$\begin{array}{l}\text { Teller characteristics } \\
\text { and behavior }\end{array}$} & $\begin{array}{l}\text { Baddeley \& Singer } \\
\text { (2008) Q1 }\end{array}$ & $\begin{array}{l}\text { Baddeley \& Singer } \\
\text { (2008) Q1 }\end{array}$ & Alea \& Bluck (2007) Q1 & Mikulincer \& Nachson (1991) Q1 & \\
\hline & & & & Mikulincer \& Shaver (2003) T & \\
\hline & & & & Baddeley \& Singer (2008) Q1 & \\
\hline & & & & $\begin{array}{l}\text { Thorne, Korobov, \& Morgan } \\
\text { (2007) Q2 }\end{array}$ & \\
\hline & & & & Aries \& Johnson (1983) Q1 & \\
\hline & & & & Bloise \& Johnson (2007) Q1 & \\
\hline \multirow{6}{*}{$\begin{array}{l}\text { Listener } \\
\text { characteristics and } \\
\text { behavior }\end{array}$} & & $\begin{array}{l}\text { Rose, Carlson, \& Waller } \\
\text { (2007) Q1 }\end{array}$ & & $\begin{array}{l}\text { Laurenceau, Feldman Barrett, \& } \\
\text { Pietromonaco (1998) Q1 }\end{array}$ & \\
\hline & & & & Reis \& Shaver (1988) $\mathrm{T}$ & \\
\hline & & $\begin{array}{l}\text { Dyregrov, 2003-2004 Q2; } \\
\text { Pietila, 2002 Q2 }\end{array}$ & & Mikulincer \& Nachshon (1991) Q1 & \\
\hline & & & & Zech, Rime, \& Nils (2004) & \\
\hline & & & & Baddeley \& Singer (2008) Q1 & \\
\hline & & & & $\begin{array}{l}\text { Lehman, Ellard, \& Wortman } \\
\text { (1986) Q2 }\end{array}$ & \\
\hline Relationship & $\begin{array}{l}\text { Bergner \& Kellner } \\
\text { (1964) T }\end{array}$ & & & Altman \& Taylor (1973) T & \\
\hline Characteristics & Nadeau (1998) Q2 & & & & \\
\hline \multirow[t]{2}{*}{ Time since loss } & & $\begin{array}{l}\text { Carnelley, Wortman, } \\
\text { Bolger, \& Burke } \\
\text { (2006) Q1 }\end{array}$ & Carnelley et al. (2006) Q1 & & \\
\hline & & Bonanno et al. (2002) Q1 & & & \\
\hline \multirow[t]{2}{*}{ Type of loss } & & Leahy (1992-1993) Q1 & & & \\
\hline & & $\begin{array}{l}\text { Middleton, Raphael, } \\
\text { Burnett, \& Martinek } \\
\text { (1998) Q1 }\end{array}$ & & & \\
\hline
\end{tabular}

Note. $\mathrm{Q} 1=$ quantitative; $\mathrm{Q} 2=$ qualitative; $\mathrm{R}=$ review; $\mathrm{T}=$ theoretical.

talk about bereavement memories, we can at least draw inferences from how people talk about other negative memories.

How a person tells a story of a negative event has a significant impact on mood. Talking and thinking about negative events in the past tense or in the third person helps to distance these events from the self concept and promote a positive mood (Kross, Ayduk, \& Mischel, 2005; Wilson \& Ross, 2003). Similarly, recalling a sad memory in detail brings it closer to the self and induces negative emotions, whereas recalling the same sad memory without the detail pushes it farther from the self and reduces negative mood (Clark, Collins, \& Henry, 1994).

Telling detailed and specific stories about bereavement and other negative life events may be painful, but it also may reflect and facilitate healthy adjustment. Distancing oneself from painful memories reflects a defensive strategy of dealing with negative affect (Singer \& Moffitt, 1991-1992). A moderate level of defensiveness is associated with optimal functioning (Weinberger, 1998). Narratives that are specific, that is, anchored in a particular moment in time, are associated with higher levels of emotional well-being and lower levels of defensiveness than narratives that are over general (Blagov \& Singer, 2004; Williams, 1996). Similarly, telling narratives of difficult life experiences in an open, exploratory way that does not minimize emotional pain enhances one's ability to complexly understand and process emotional experience-a key aspect of mature identity development (Pals, 2006). For these reasons, narrative psychotherapists may encourage clients who repeat the same maladaptive story about a negative life event to tell the story in more vivid detail, thus evoking a richer representation of the experience from which to draw more adaptive meanings (Neimeyer \& Levitt, 2001). However, listeners should be prepared for a greater expression of emotional intensity as the individual moves toward a more sensory, rich evocation of the experience.

The influence of disclosure characteristics on the interpersonal challenges addressed by bereavement narratives. To effectively serve the social challenges of teaching and informing or maintain- 
ing or developing intimacy, narratives must be able to capture and hold a listener's attention. This means that there are some elements, like coherence, that are important for effectiveness regardless of which social challenge is being addressed. However, some disclosure characteristics may differentially influence the effectiveness of narratives in serving particular challenges. For example, the building of intimacy may be facilitated by narratives that are personally revealing and rich in emotion, whereas the continuing bonds challenge may best be served by disclosures that focus on positively toned, vivid, and detailed recollections of the loved one. This section focuses on narrative characteristics that make a narrative - and by extension, the narrator-acceptable to listeners. Acceptance is an especially important precondition for intimacy, and it may also facilitate the other social challenges, continuing bonds, and teaching life lessons, although its role is less clear with regard to these other challenges.

Narratives that are rich in emotion and detail are especially powerful ways of making oneself known to a listener (Alea \& Bluck, 2003). Yet the sharing of bereavement stories for the purpose of building intimacy may backfire when the stories involve, as they often do, a great deal of negative emotion. Negative self-disclosures such as bereavement narratives may convey vulnerability. Thorne and McLean (2003), in study of telling traumatic events in adolescence, found that these narratives fell into three categories according to the positioning of the narrator: one category in which the narrator described the self as standing up to challenges, another category in which the narrator described compassion for the suffering of others; and a third position — called the vulnerability position-in which the narrator described preoccupation with his or her own suffering. Participants in the Thorne and McLean study also told stories about times when they told the story, and about listeners' responses. Vulnerability narratives were more likely than the other two types to elicit rejection.

Vulnerability is a problematic stance to assume in interpersonal interactions because it places implicit demands on the recipient to help or comfort the discloser. According to Brown and Levinson (1987) and Goffman (1967), people have two basic sets of needs or motivations in social interactions: negative face needs (the motivation to avoid being bothered or interfered with by others) and positive face needs (the motivation to be thought well of by others). The demands for comfort and support implicit in a story that conveys vulnerability create a tension between the recipient's negative face needs (which might lead him or her to withdraw from the conversation) and his positive face needs (which would lead him or her to comfort and generally act kindly toward the narrator; Tracy, 1990). This tug-of-war between these two evoked motives may make the interaction awkward for the recipient and may lead to rejection or withdrawal.

The vulnerability that a narrative conveys is shaped not only by the kinds of emotions that are disclosed but also by the factual content of the story (e.g., who died and when), the goals that the narrator articulates, and contextual factors like how and when the story is introduced (i.e., precontext and timing). An adult who has lost a young child will probably (and perhaps appropriately) be thought of as more vulnerable and distressed than an adult who has lost an aging parent. Someone who tells a story of the loss of a loved one to suicide may be viewed as more vulnerable than someone who tells the story of a loved one who has died in a heroic act.
Vulnerability is partly conveyed through the nature of and sequence of the emotions and/or goals articulated in a narrative. The goals expressed in a narrative and the emotional impact of the narrative are, from the point of view of the recipient, closely linked (Ozyurek \& Trabasso, 1997). Ozyurek and Trabasso found that when a narrator articulated or initiated a new goal subsequent to his or her failure to achieve a former goal, readers perceived a positive emotional turn to the narrative. It is noteworthy that for the tone of a narrative to go from negative to more positive, the mere introduction of new goals is enough; goals do not have to be achieved, nor plans laid out, nor do positive emotional experiences have to be explicitly articulated.

A central part of bereavement is the loss of valued goals (e.g., watching one's children grow up or living into old age with one's spouse). Yet in "redemption" stories (McAdams, Reynolds, \& Lewis, 2001), the narrators are able to at least construct a plausible, future-oriented goal without which a sense of purpose is impossible. The following is an example of such a narrative:

My husband was killed in action in Iraq. I was 28 at the time with a young daughter. Her well-being is my most important goal. I lost my white picket fence and the life we had made for ourselves. There was a fork in the road of life-let this tragic event consume me or embrace the life I have now. I choose the latter.

This story speaks of the narrator's dedication to a goal (the daughter's well-being), which gives her life purpose. Contrast this with the narrative that began this paper. That narrative, a contamination sequence (i.e., a narrative in which an initially positive event or situation is spoiled by a bad outcome, McAdams et al., 2001), dwelled on a failed goal, and did not indicate the initiation of any new goals. Without goals, the narrator is without purpose. The failure to articulate a goal that might be achievable gives the contamination narrative its pathos, whereas the redemption narrative gains its sense of hope in part from the narrator's articulation of a new goal. Confirming that stories without positive future goals are harder for recipients to hear, Baddeley and Singer (2008) found that contamination sequences evoked more sympathetic concern but less acceptance and greater social awkwardness in recipients.

Disclosure variables such as precontext and timing also shape the story's effectiveness in successfully meeting the social challenges associated with bereavement. Whenever a disclosure is shared in conversation, the precontext (i.e., the remarks that precede the disclosure) shapes how the listener interprets the disclosure, and thus shapes the social effects of the story (Holtgraves, 1990). Without a precontext that makes a disclosure relevant, the disclosure is likely to seem jarring and awkward. Asking others to disclose appears to be a good way of making a precontext for a disclosure (Holtgraves, 1990), perhaps because of reciprocity norms. In addition, disclosures are less jarring if they are introduced toward the end rather than toward the beginning of a conversation. If they are disclosed further along into the development of the conversation, the listener is likely to feel that the teller has been more prudent and selective in the choice of recipient and timing for her disclosure, and the listener is likely to feel more honored to receive the disclosure. This effect may be especially important in building intimacy (Holtgraves, 1990). Listeners may also provide a precontext by asking questions that elicit a disclosure or by raising topics from which the disclosure is a natural segue. 
A precontext is a necessary but not sufficient condition for a disclosure to be acceptable. Even when it is the listeners who are soliciting the disclosure, they may not feel comfortable with the disclosure that they hear. Their conflicting negative- and positiveface needs may lead them to engage more in the conversation than is comfortable for them. Even though the listener's responses to the teller may still be warm and encouraging (to satisfy the listener's positive face needs), the listener may subsequently socially reject the teller (to protect his or her own negative-face needs).

The telling of rich and detailed autobiographical memories of loss may facilitate the maintenance of continuing bonds with the deceased loved one. Alea and Bluck (2007) found that after recalling autobiographical memories of time spent with a significant other, women reported increased feelings of closeness and warmth and men reported increased feelings of warmth toward the significant other. For women, the more the memories they recalled included communal themes, the more warmth and closeness they felt. This suggests that, at least for women, telling a story of loss that entails themes of communion (e.g., spending last moments with the loved one before the death) may promote the maintenance of continuing bonds with the loved one.

Finally, narratives that are offered with appropriate precontext and elaborated detail are more likely to capture listeners' attention and imagination, thus ensuring that they will be more likely to carry forward their lessons to the listeners. Narratives that contain explicit meaning making statements to accompany their evocative imagery reflect better adjustment in the tellers (Blagov \& Singer, 2004) and therefore model coping and adjustment for recipients of these disclosures.

\section{Teller Characteristics}

The influence of teller characteristics and behavior on the intrapersonal challenges addressed by bereavement narratives. Although there are many possible features of tellers (and of listeners) that might contribute to the shaping of narratives (e.g., age, gender, personality, experience with loss, emotional intelligence), we necessarily focus only on a selected few of these possible influences. Tellers' personality and worldview shape their behavior in a storytelling interaction, influence the way that the story is told and the way that listeners' behavior is interpreted, and thereby influence how effectively intrapersonal challenges are addressed. Tellers who are high in neuroticism are likely to tell more selffocused stories and contamination sequences, and these stories are likely to be aimed at addressing intrapersonal rather than interpersonal challenges of bereavement (Baddeley \& Singer, 2008). Audiences report more social awkwardness and less acceptance of contamination narrators (Baddeley \& Singer, 2008). Together, these findings suggest that narrators high in neuroticism tell stories that may result in diminished social support, which may in turn interfere with the intrapersonal challenges of emotional recovery and identity reconstruction.

Next, tellers' expectations regarding others' benevolence or malevolence, responsiveness or negligence, shape the stories told in the interaction, and the outcomes of the interaction (Holmes, 2002). These expectations in turn will shape how a storyteller will respond to a listener's reactions. For example, a teller who per- ceives others as unresponsive may interpret a listener's ambiguous silences as cold or unfriendly, whereas a teller who perceives others as responsive may interpret the same silences as sympathetic. These interpretations will shape the direction of the story and the interaction: The former storyteller may feel misunderstood and hurt, curtail the story, and prematurely end the interaction, whereas the latter storyteller may feel comforted and able to proceed with more intimate disclosures. These disclosure outcomes are likely to influence the degree to which tellers feel uplifted by their disclosure and able to sustain self-confidence in their efforts to forge a reconstituted sense of positive identity and meaning.

The influence of teller characteristics and behavior on the interpersonal challenges addressed by bereavement narratives. Personality variables such as attachment style influence people's reasons for disclosing, the kinds of disclosures they make, and the audiences they choose for their disclosures (Mikulincer \& Nachshon, 1991; Mikulincer \& Shaver, 2003). Securely attached and ambivalently attached individuals tend to be more emotionally expressive and are more likely than avoidantly attached individuals to engage in self-disclosure across a range of interpersonal situations (Mikulincer \& Nachshon, 1991). Thus, both securely and ambivalently attached individuals would be more likely to make detailed and emotional disclosures regarding a loss than would avoidant individuals. Securely attached individuals are more likely to be able to effectively develop intimacy through telling stories. Securely attached individuals vary the extent to which they disclose personal information, depending on the circumstances of the social situation. They tend to be responsive to others' self-disclosures and to disclose at a level that matches the level of disclosure of the person with whom they are interacting, a strategy that is ideal for building intimacy (Mikulincer \& Shaver, 2003). Ambivalently attached individuals, by contrast, tend to make personal disclosures indiscriminately (e.g., to audiences who are less likely to desire intimacy, such as strangers and people who tend not to self-disclose) and to be unresponsive to others' selfdisclosures (Mikulincer \& Nachshon, 1991).

People with a secure attachment style tend to be higher in extraversion compared to those with ambivalent or avoidant attachment styles (Mikulincer \& Shaver, 2007), and the findings for how people high in extraversion tell stories are consistent with findings for securely attached individuals' disclosures. Specifically, people high in extraversion tend to use their stories to address social challenges such as intimacy development more often and with greater success than do people lower in extraversion (Baddeley \& Singer, 2008; Thorne, Korobov, \& Morgan, 2007).

There are consistent gender differences in memory for and willingness to discuss intimate and emotional events. Women can remember emotional events better than men can, but this is mediated by emotion sensitivity (Bloise \& Johnson, 2007). Women also tend to disclose more intimate life events and talk in more depth about these events than men do (e.g., Aries \& Johnson, 1983), which may maximize the likelihood of achieving intimacy with one's listeners and create an enhanced sense of connection with the deceased (cf. Alea \& Bluck, 2007). These more extensive disclosures may also serve an advice giving and lesson learning function that provides a source of shared practical wisdom among women. 


\section{Listener Characteristics and Behavior}

The influence of listener characteristics and behavior on the intrapersonal challenges addressed by bereavement narratives. Responsiveness and emotional validation may encourage people to open up and tell their story in a more exploratory manner, which may facilitate both the exploration of goals and purposes, and may facilitate emotional recovery. If listeners respond more empathically, this will give the teller more opportunity to express and refine a perspective, which may be helpful. There is a danger, though, that supportive, empathic listeners may encourage rumination, an excessive focus on problems and the expression of negative emotion. Corumination has been studied in children and adolescents, and in girls, it has been shown to promote increased depression and anxiety over time, even as it promotes increased friendship quality in boys and girls (Rose, Carlson, \& Waller, 2007). Conversely, mood-induction research has shown that individuals in a negative affective state perceive listeners' empathic comments as more beneficial for the relationship, but benefited more emotionally when listeners offered reappraisals instead (Nils, 2003; as cited in Zech et al., 2007). It is possible that some support groups, in which sympathetic listeners encourage other bereaved individuals to discuss their problems, may be promoting the growth of friendships between members but perpetuating members' negative emotions.

Bereaved people sometimes report disjunctions between the kind of support that they would like and the ways that others respond to them and their loss. The kinds of responses that bereaved individuals frequently report as unhelpful include others' avoidance of them or the subject of their loss along with others' unsolicited advice (Dyregrov, 2003-2004). Based on interviews with suicide-bereaved individuals, Pietila (2002) observed that these individuals want not only empathic support and validation of their pain, but acknowledgment of their special position as individuals who have suffered such a loss. The bereaved consider others' responses to their disclosures as satisfactory to the extent that they express neither too little nor too much involvement in the loss, but rather acknowledge the bereaved individual's special ownership of their loss and the pain that it entails. In other words, they want their experiences acknowledged, and such acknowledgment can be the basis of coconstruction of a loss narrative that can contribute to identity development.

The influence of listener characteristics and behavior on the interpersonal challenges addressed by bereavement narratives. Recipients greatly shape the effects of a disclosure by how they respond. For tellers who seek to retain connection with the departed individual, empathetic listeners can reinforce the strength and value of the teller's relationship to the lost loved one by validating the significance of the loss story to the teller. If the goal is to build intimacy with the living, it is equally important that recipients convey understanding, validation, and positive regard for the teller in his or her own right (Laurenceau et al., 1998; Reis $\&$ Shaver, 1988). In general, securely attached people tend to be more responsive during these interactions (Mikulincer \& Nachshon, 1991). When a listener agrees with a teller's version of events, the teller feels more emotionally close to the listener (Zech et al., 2004).

Telling stories that reflect sustained negative affect and hopelessness may discourage intimacy, but may be less likely to do so when the listener is high in extraversion; individuals who are high in extraversion report feeling more sympathy and concern for contamination narrators (Baddeley \& Singer, 2008). In actual conversations, though, it is unclear how extraverts' more sympathetic attitudes would translate into behavior, and how this behavior would influence the exchange. If extraverted individuals express their sympathy with empathic facial expressions, this may promote a feeling of intimacy. If extraverted individuals express their sympathy with platitudes, for example, "I know how you feel," then this may backfire and alienate the bereaved individual (Lehman, Ellard, \& Wortman, 1986).

\section{Relationship}

The influence of the relationship between listener and teller on the intrapersonal challenges addressed by bereavement narratives. The relationship between teller and listener plays a role in shaping the outcomes of story disclosure. The relationship is strongly shaped by the social roles that each person inhabits, such as parent, child, employee, professional, lover. Social roles play a significant role in permitting, proscribing, or encouraging discussions of personal or emotionally intense topics. Work relationships are an arena in which social norms may proscribe the disclosure of emotionally intense, personal stories (Hazen, 2003), which may limit the potential of disclosure in these contexts for identity exploration and development. In contrast, relationships like marriages or close friendships are key arenas for discussions of personal, emotionally intense topics, and for the revision of identity that the telling of bereavement stories may accomplish.

In their influential theoretical work, Bergner and Kellner (1964) argued that marriages are the primary arena in which (married) individuals decide on meanings and interpretations for the events in their lives. Nadeau's (1998) analysis of intensive interviews conducted with bereaved families supports the view that family discussions are a primary arena in which the family members make sense of the loss. Yet close relationships may sometimes inhibit the development of new understandings of events and place constraints on what can and cannot be said. In close relationships in which role expectations for the teller are minimally constrained, then, bereaved people may feel freer to engage in more narrative exploration, an important process for the development of a mature, complex identity (Pals, 2006).

The influence of the relationship between listener and teller on the interpersonal challenges addressed by bereavement narratives. Regarding the social challenge of maintaining a continuing bond with the deceased, bereaved individuals may experience grief support groups as the only place their continuing relationship with the deceased loved one is acknowledged and validated. One mother who experienced the loss of her unborn child wrote, "it is only during those meetings that [my deceased child] is recognized as my son and I'm allowed to acknowledge my pain" (Baddeley \& Singer, 2008). The support group becomes, perhaps, the only place in which bereaved individuals can coconstruct a narrative that incorporates the ongoing presence of the deceased in their lives. Indeed, support groups for bereaved parents often feature rituals in which bereaved parents express their continued connection with their deceased child. In some groups, for example, meetings end with each member addressing his or her deceased child by name and speaking to them. In these groups, the telling of the story of 
how the loved one was lost would be both expected and encouraged as a way of expressing both healthy grief and further disclosure about the relationship with the departed.

People prefer to share emotionally intense events with friends, partners, or family members rather than with strangers (Rime, Batja, Philippot, \& Boca, 1991). And indeed, more intimate story disclosures are more appropriate with close friends (Altman \& Taylor, 1973). Bereavement narratives may be too intimate for disclosure between people who do not know each other very well and may inhibit the development of intimacy in such relationships. There is evidence that close relationships may also be strained by telling stories about bereavement. Interviews with bereaved individuals suggest that the bereaved do experience social responses such as avoidance-even from friends - that are suggestive of a breakdown in a relationship (Dyregrov, 2003-2004). Thus, telling negative stories about one's loss repeatedly may damage one's relationships.

\section{Time Since Loss}

The influence of time since the loss on the intrapersonal challenges addressed by bereavement narratives. In most cases, as time passes since the loss, people talk about their loss less frequently and feel less negative emotion when thinking about the deceased (Carnelley et al., 2006). There are exceptions to this rule; sometimes people feel social pressure to stay silent about their losses and do not talk about them until much later. Harvey et al. (2001) described the decades-long silence that some veterans reported keeping regarding their memories of loss during wartime. As time passes, the type of story that is likely to be told changes, for example, a bereaved person is less likely to tell a contamination story about his or her loss (Baddeley \& Singer, 2008) and is more likely to mention positive rather than negative outcomes of the loss (Miles \& Crandall, 1983). In the early period right after the death, then, the emotional recovery challenge may be more prevalent than it is weeks, months, or years later.

The addressing of the emotional recovery challenge is likely to depend on how distressed the person is and how distressing their story is as well as on the availability and willingness of listeners to hear the loss story. All of these may be affected by the passing of time since the loss. Generally, people's level of distress about a loss fades over time, and there are distinct individual differences in bereaved individuals' trajectories of emotional response after loss, and thus, in the kinds of loss stories they are likely to tell (Bonanno et al., 2002). In Bonanno et al.'s framework, individuals who are resilient-experiencing relatively low levels of distress after the loss-may be able to tell a story that conveys strength and hope from early on after their loss. People on a recovery trajectory (high distress initially, but recovery fairly quickly) may tell very sad stories soon after the loss, then more hopeful stories as time goes on. Chronic grievers are likely to keep telling very sad stories in the hopes of feeling better or receiving comfort or support for their pain.

Listeners' willingness to listen to detailed recountings of others' emotional experiences (at least of disruptive collective or public events) decreases over time, with some empirical evidence pointing to sharp decreases in willingness to listen about 2 weeks after the event (Pennebaker \& Harber, 1993). Pennebaker and Harber investigated patterns of social sharing among San Francisco bay area residents following the Loma Prieta earthquake and among Dallas, Texas residents following the initiation of the $1991 \mathrm{Gulf}$ war. They found during the first 2 weeks after each event happened-a period they termed the emergency stage - people talked frequently about the event, and that during the subsequent 6 weeks, which they termed the inhibition stage, people still thought about the event but were no longer interested in hearing about others' experiences of the event. It seems plausible that this social stage model would also apply to the disclosure of personal negative events like the loss of a loved one, given that it is a common observation among the bereaved that their friends tire of talking about the bereaved person's loss more quickly than the bereaved tire of telling about their loss.

No work that we know of explicitly addresses the question of when, after a loss, people are struggling with identity reconfiguration; indeed, bereavement research seems to have foregone the idea of explicit stage models or time frames for such processes. Identity reconfiguration may be a lifelong undertaking, or it may fade over time.

It may be that within the first 2 weeks after a loss, one has one's best shot at finding an audience willing to offer support, advice, and comfort, but the time frame during which people will be willing to listen to a bereaved person's story may depend on the story — and the goals - as well. As time passes after the loss and the window for social support closes, people may withdraw from others who continue to dwell on past hurts without evident progress. This diminishing of available social support as time passes may limit how successfully either of the intrapersonal challenges of loss may be navigated.

The influence of time since the loss on the interpersonal challenges addressed by bereavement narratives. It is possible that individuals who speak too openly and graphically about their loss in the immediate aftermath of their grief may be considered to still be in the throes of shock or at risk for a major depressive episode. The nakedness of their sorrow, undiluted by time, may raise concern in others and undermine the bereaved individuals' attempts to develop or maintain stable social bonds with their listeners. In such cases, the listeners may feel powerless to help the narrators and encourage them to seek support from their physician, counselor, and/or clergy. Bereaved people are typically less focused on continuing bonds with the deceased as the months pass (Carnelley et al., 2006) and may less frequently tell stories for the purpose of keeping the loved one's memory alive.

The opportunities for using one's story of loss to teach and inform may increase over time as one gains perspective on the loss; the passing of time brings a less frequent experience of negative emotion (Carnelley et al., 2006) allowing for a renewal of hope, and therefore the construction and sharing of the kinds of inspirational narratives that tell of the possibility of hope after a major loss (see Harvey et al., 1992).

\section{Type of Loss}

There are no concrete comparative data on how individuals who have suffered different forms of bereavement tell stories about their loss or how these stories address particular coping challenges. In the absence of such data, it is still possible to piece together how the purposes of bereavement storytelling might vary by type of loss. First, there are the psychological and social needs and goals 
of the bereaved, which should vary as a function of loss and its circumstances and should influence the type of intrapersonal and interpersonal challenges that would be most salient for the bereaved in sharing their loss story. Second, there are the social circumstances of the bereaved (e.g., the availability of social support) that should vary as a function of the type of loss and the type of story that gets told and should influence which coping challenges can be effectively served in conversation.

The influence of type of loss on the intrapersonal challenges addressed by bereavement narratives. One factor that would shape a bereaved individual's psychological needs is the amount of distress the person is in-and distress does differ across different kinds of bereavement. Comparative studies of bereaved parents, bereaved spouses, and bereaved adult children found that bereaved parents showed more intense and long-lasting distress (Leahy, 1992-1993) and grief (Middleton, Raphael, Burnett, \& Martinek, 1998) than bereaved spouses, who in turn showed longer and more intense distress and grief than bereaved adult children. This suggests that bereaved parents would have the greatest need for emotional recovery. Losing a child may be more threatening to identity and a sense of meaningfulness in the world than losing a parent during adulthood, given that the loss of an aging parent is a normative and expected part of adult life.

The circumstances of the death (e.g., violent, sudden death vs. peaceful, expected death) affect bereaved individuals' responses to the death. Violent death increases the chance of complicated grief (also known as traumatic grief) and makes it less likely that the bereaved will report that they were able to make sense of the death (Currier, Holland, \& Neimeyer, 2006). When people who are undergoing traumatic grief talk about their loss, their stories are less likely to contain positive themes (Maercker, Bonanno, Znoj, \& Horowitz, 1998) and more likely to show a failure to find meaning and come to terms with the loss. Their stories are less likely, therefore, to be socially acceptable to others and are more likely to engender discomfort and avoidance on the part of potential listeners, which may disrupt the potential for gaining social validation and feedback in the work of building identity or meaning. Individuals who have experienced what are known as disenfranchised losses, that is, losses whose significance is not socially recognized or validated (e.g., the loss of a child with a mental or physical handicap, the loss of a fetus through miscarriage) may have similar trouble getting appropriate social support for the telling of their story, and again, the identity and meaning challenges may be difficult to address.

The influence of type of loss on the interpersonal challenges addressed by bereavement narratives. How might social needs vary between bereaved individuals who have had different kinds of losses? Bereaved individuals who have had nonnormative losses (e.g., loss of child or disenfranchised loss of some kind) may find themselves more socially isolated as their friends find it difficult to be around them (Rosenblatt, 2000). The causes of this social isolation are not entirely clear. The type of loss per se may play a role, as might the characteristics of the story that is told about it. It is difficult to distinguish between these two because, as noted in the last section, people who have less normative, more traumatic losses tend to tell stories that reflect a greater level of despair. Regardless, individuals with these less normative losses may have a greater need to forge new socially intimate connections. Their ability to do this is likely to depend a great deal on the timing and precontext of the disclosure. Stories about nonnormative losses probably seem more personally revealing and intimate, and as a consequence, they may interfere with intimacy if poorly timed or shared with wrong person but might significantly contribute to intimacy if timed well and shared with a receptive listener.

The emotional impact of nonnormative, traumatic deaths may be harnessed to powerfully address the teach/inform challenge of bereavement, for example, by raising community awareness about particular issues (e.g., homophobia, drunk driving). When the death is a normative experience like the death of an older parent, the teach/inform challenge might still play a role, but perhaps on a smaller, less dramatic scale, for example, in conversations that the midlife adult has with peers who have aging or dying parents and are expecting to face a loss of their own.

\section{Discussion}

The specific model that we have proposed for the sharing of bereavement narratives bridges the autobiographical literature and the bereavement literature. The main contribution of the model is to provide a framework for further empirical study of how social interactions can help or hinder people in addressing the challenges that are central to adaptation after bereavement. The model is a response to recent work on bereavement that has said that adapting to bereavement is a process of narrative building (Neimeyer, 2001) and, more important it is an interpersonal process rather than simply an intrapsychic one (Hagman, 2001), although most theories and empirical studies have focused on intrapsychic processes. Studies that have explored the interpersonal processes involved in adaptation to bereavement are few, and still largely descriptive. It should also be noted that the literature that has formed the basis for our model draws on evidence and theory from the Western world. Thus, our model should not be assumed to be cross-culturally applicable.

Our bereavement-specific model breaks down the complexity of social interactions into variables that can be systematically studied. Our coverage of the available literature (see Table 1) shows gaps in the evidence for how particular kinds of stories told in particular social contexts might address some of the challenges of bereavement. There is a fair amount of evidence for what kinds of stories, narrators, listeners, relationships, time frames, and types of losses best promote emotional recovery. This may be because mental health outcomes have obvious significance and can be measured with relative ease, using established self-report instruments. There is also a fair amount of evidence that speaks to what kinds of stories, narrators, listeners, relationships, time frames, and types of losses promote intimacy development, although some of the available evidence does not directly assess intimacy as an outcome, but rather variables that are prerequisites to intimacy, for example, social acceptance and liking.

There is scant research evidence regarding the social circumstances that facilitate the continuing bonds challenge and the teaching life lessons challenge. The transmission of a life lesson may be difficult to measure. Would it be measured by a change in the receiver's thoughts or behavior? Its effects may be seen much later than the story is told, for example, the story may be remembered and its lessons applied years later when the receiver is in a similar situation to the narrator. As for continuing bonds, there are 
accepted measures for continuing bonds, but research has not systematically examined how bereavement narratives and the social context in which they are told affect the strength and quality of these bonds.

Identity and meaning reconstruction are key aspects of grieving, according to the constructivist view of bereavement (Neimeyer, 2001). However, the influence of narrative characteristics and the characteristics of the social context in which narratives are told on the reconstruction of identity, meaning, and purpose has not been systematically investigated.

For the sake of clarity, we discussed five separate challenges associated with bereavement. In reality, these challenges are interrelated. For example, having supportive social bonds is associated with greater emotional well-being (W. Stroebe, Zech, Stroebe, $\&$ Abakoumkin, 2005). The meaning that can be found in a loss may come from strengthened interpersonal relationships and a sense of ongoing connection with the departed (Wheeler, 2001). In addition, we discussed the different factors in the model (teller and listener characteristics, relationship, content of the narrative, time since loss, and type of loss) one by one. In reality, all of these factors are operating simultaneously and in interaction with each other in the disclosure of bereavement narratives in social contexts. Using as an example of the story from the anonymous participant that began this paper, imagine that the storyteller decides to tell this story to an old friend whom she has not seen in many years, but with whom she used to discuss personal problems and worries. One can imagine the story being told angrily, or with sadness, or something in between. Depending on her friend's dispositional comfort with particular kinds of emotion, it may be easier for the friend to empathize with anger rather than sadness, or vice versa.

The relationship between them may be such that the friend feels comfortable hearing the story, perhaps because hearing a story of a personal problem reminds her of their old intimacy. If this is the case, the friend is likely to invite more disclosure, which would lead to a deepening of the intimacy. On the other hand, the friend may feel uncomfortable with hearing the story, but also feel a sense of obligation to her old friend, resulting in ambivalence and perhaps avoidance.

The time since the loss will doubtless play a role; if the loss happened very recently, the narrator's reaction would be understandable to almost anyone. If the loss happened years ago, few people would be comfortable hearing the story as expressed by the narrator. An exception might be a strong relationship in which the listener is aware of the teller's ongoing despair, but loves her anyway. The type of loss makes a difference, too. Given that the story deals with the loss of a romantic partner in a senseless accident, the narrator's focus on her own despair may be understandable in a way that it would not be if her romantic partner had died heroically in battle. In real conversations, though, the "type of loss" becomes nuanced.

Imagine that the friend has a negative impression of the deceased partner, for example, that he was an abusive, self-centered man. In this case, the friend is unlikely to provide much agreement or empathy with the teller's contention that her best days are behind her. If the friend agrees that the deceased partner was wonderful for the bereaved, she would be able to express more validation and empathy. These different reactions would produce different results from the teller. The teller is likely to sense a lack of empathy or agreement and may react negatively (e.g., by with- drawing or becoming angry) and curtail the story in response. If the listener conveys the idea that "you will find someone else to love" this may or may not be a useful thing for the teller to hear. Its usefulness may depend on the teller's personality and how much time has passed since the loss. If the teller feels extremely hopeless and it is very soon after the loss, such a statement would probably feel like an insensitive platitude, reinforcing the teller's sense of alienation and hopelessness. If more time has passed since the loss, such a statement might help to build the teller's hope for social connectedness.

As this example makes clear, all of these social interactional variables have the potential to influence independently and conjointly the effectiveness of a loss disclosure in meeting the challenges posed by bereavement. Blanket statements about the positive or negative value of telling the story of one's loss seem simplistic in light of the multiplicity of influence detailed in this model. Future research can begin to systematically manipulate the social interactional factors that accompany these disclosures and examine subsequent effects on the efforts to meet adjustment challenges.

The model that we presented here was specific to bereavement, but the effectiveness of this approach makes a compelling argument for the value of adapting the general memory-telling model to other specific types of memory narrative disclosures, such as autobiographical memories of coming out of the closet (e.g., King \& Noelle, 2005) or being in trouble with the law (e.g., Maruna, 1997). In both of these cases, a specific model would include specific functions (e.g., in the case of coming out stories, advocating for gay rights; in the case of criminal stories, warning others of the pitfalls of criminal activity), listener characteristics (e.g., in the case of coming out stories, homosexual or heterosexual), and other components.

\section{Clinical Implications of This Bereavement Disclosure Model}

Most bereaved individuals can, over time, resume normal functioning and find joy in life again. Bereaved individuals who remain stuck in pain, despair, and distress long after their loss may be sharing their stories a great deal (Rime, 1995) and are likely to be out of step with the expectations of their friends and family, who may grow weary of their unremitting misery. Thus, the people who most need help in reconstructing their story may lack the social resources that could help them to think of different perspectives and coconstruct a more adaptive story. As many grief counseling researchers have argued, therapists can fill an important role by providing a safe and empathic space for these grievers to share their stories, receive validation, and gradually revise their story to include more hope. We propose that therapists and other helping professionals, such as death education providers and pastoral counselors, might serve a valuable function in educating clients to share their stories in ways that are context appropriate-mindful of the listener's goals and needs as well as the teller's. Below, we review some ways that therapists might intervene to help clients revise their stories and share their stories in context-appropriate ways.

The challenge for all therapists is how to help clients change their personal stories into stories that provide them with purpose and hope. Narrative therapists have argued that it is important for clients to elaborate on the scantly detailed, constricted stories that 
they tell, particularly if these stories contain interpretations that are maladaptive. Elaborating on the story-telling it in more detail and with more emotion - can provide enough additional information and complexity to challenge the negative or unhelpful interpretations that the client had made. A major question that bereaved people often face as they try to make sense of their losses is "Why did this have to happen?" This may lead bereaved individuals to engage in counterfactual thinking - thinking about how the death might have been prevented-a habit of thought that often ventures into excessive self-blame and is associated with prolonged distress (Davis, Lehman, Wortman, \& Silver, 1995). For example, one of us knows of a woman whose ex-husband murdered their children while the children were at his house for a weekend visit. This woman continually told herself, quite unrealistically, that she could have prevented her children's death. A therapist treating this client might ask the client for a detailed recounting of her story to provide grounds for challenging the person's feelings of guilt and self-blame as well as uncover and develop desires or goals that the person might have for the future (e.g., developing new relationships while still honoring the deceased). Including these goals in the story would be likely to make the story feel less burdensomely negative to the listener.

Aside from helping clients tell more adaptive, hopeful stories, therapists can help clients to share the stories that feel true to them more judiciously - and sometimes these will be stories that contain a great deal of pain and hopelessness. Bereaved clients in therapy may-quite naturally and understandably - tend to be quite selfcentered. The literature on bereavement offers guidelines for helping others interact and effectively support the bereaved, but we propose an additional set of guidelines: How to help the bereaved effectively interact with others. We anticipate that these guidelines will be most appropriate and useful for individuals for whom some time has passed since their loss, but who remain "stuck" or feeling hopeless in their grief. Clients are likely to be better able to share their painful stories in ways that effectively address the challenges of bereavement if they maintain awareness of how the telling affects their listeners. Here are some potential guidelines that can be drawn from the research reviewed in this paper.

Make the story relevant to your listener. Listeners need to know why they are being told things, especially things that are emotionally burdensome. By setting appropriate precontexts for the story's telling, the teller will better prepare the listener for the painful narrative that ensues. Tellers should choose appropriate circumstances of privacy and ensure that there are ample time parameters before launching into such a demanding disclosure. Tellers should alert the listeners that they are about to talk about a topic of great intensity and feeling and give the listener more than one opportunity to opt out of the dialogue. Tellers should also give assurances to the listeners that they are freely choosing to share this narrative and that they feel it will be helpful and of value for them to do so. As the narrative unfolds, they might periodically check with the listener to assess their comfort level and willingness to continue the dialogue.

Different listeners need different intensities of emotional information. It may be socially beneficial to suppress negative emotion around people who are not interested in becoming intimate with the teller but better to express such emotion around people who are intimates of the teller or interested in becoming that way.
All of this does not mean that clients should try to tell stories according to a rigid formula that describes what is healthy or adaptive. Rather, when clients can be flexible in how they tell the story, they can find out for themselves how best to tell it in different contexts to achieve the aims of the disclosure. An awareness of the many ways that there are to tell any given story (e.g., which events to start and finish with, how concrete and detailed, how emotional, how abstract and integrative to be) may allow the bereaved to tailor their stories better to their social contexts.

It may be difficult for individuals early in their grief to modulate their disclosures and make careful choices as to whom and when they might disclosure. Yet as time since the loss accumulates, the bereaved individual may find the assistance of a therapist or counselor in differentiating how to make more effective disclosures invaluable in meeting the goals of emotional recovery, identity reconfiguration, and building intimacy with supportive listeners. Careful selective disclosures may deliver on the promise that so many grief counselors attach to the concept of "letting it out" and "talking about your loss."

\section{Summary}

This review has demonstrated that general statements about the necessity or the therapeutic benefit of bereavement disclosure are far too sweeping and inaccurate. Bereavement disclosure is best considered in a functional and interactional context that reflects a concern with both intrapersonal and interpersonal dimensions of disclosing a loss. Mounting empirical and theoretical work points to the need to evaluate the personality characteristics of the discloser and listener as well as the characteristics of the dyadic interaction. The goals of the disclosure, whether for emotional release, insight, social support, intimacy, advice giving, or some combination of any and all of these adjustment challenges, must also be considered and examined for their influences on disclosure effects. Further, the content, grammar, structure, and emotional intensity of the narrative itself are all likely to play a role in the reception of the disclosure and whether it will lead to a positive or negative outcome for the narrator. Finally, the amount of time that has elapsed since the original loss and the type of loss may also affect the quality, reception, and outcome of the disclosure.

Clearly, the application of autobiographical memory telling research to the topic of bereavement disclosure alerts both researchers and clinicians to the risks of a naïve advocacy of disclosure, as has sometimes been promoted by grief counseling professionals. The act of telling another person about a painful loss in one's life is a complex social phenomenon that is likely to have a powerful impact for both discloser and listener. If we are to maximize the benefits for individuals seeking to make loss disclosures, the current review highlights factors that should be considered prior to these disclosures. By evaluating the goals of the disclosure, one's own personality traits and the traits of the intended recipient of the disclosure, individuals and their helping professionals can work to optimize the benefits and minimize the costs of sharing their intimate stories of loss with others. The application of a memory telling model will assist them in this assessment. 


\section{References}

Alea, N., \& Bluck, S. (2003). Why are you telling me that? A conceptual model of the social function of autobiographical memory. Memory, 11, $165-178$.

Alea, N., \& Bluck, S. (2007). I'll keep you in mind: The intimacy function of autobiographical memory. Applied Cognitive Psychology, 21, 10911111.

Altman, I., \& Taylor, D. A. (1973). Social penetration: The development of interpersonal relationships. Oxford, England: Holt, Rinehart, \& Winston.

Archibald, L. (n.d.). To the newly bereaved after suicide. Retrieved March 1, 2008, from http://www.survivingsuicide.com/breaved.htm

Aries, E. J., \& Johnson, F. L. (1983). Close friendship in adulthood: Conversational content between same-sex friends. Sex Roles, 9, 11831196.

Aron, A., Melinat, E., Aron, E., \& Vallone, R. D. (1997). The experimental generation of interpersonal closeness: A procedure and some preliminary findings. Personality and Social Psychology Bulletin, 23, 363-377.

Attig, T. (1996). How we grieve: Re-learning the world. New York: Oxford University Press.

Baddeley, J. L., \& Singer, J. A. (2007). Charting the life story's path: Narrative identity across the life span. In D. J. Clandinin (Ed.), Handbook of narrative inquiry: Mapping a methodology (pp. 177-202). Thousand Oaks, CA: Sage.

Baddeley, J. L., \& Singer, J. A. (2008). Telling losses: Personality correlates and functions of bereavement narratives. Journal of Research in Personality, 42, 421-438.

Bergner, P., \& Kellner, H. (1964). Marriage and the construction of reality: An exercise in the microsociology of knowledge. Diogenes, 46, 1-24.

Blagov, P. S., \& Singer, J. A. (2004). Four dimensions of self-defining memories (specificity, meaning, content, and affect) and their relationships to self-restraint, distress, and repressive defensiveness. Journal of Personality, 72, 481-512.

Bloise, S. M., \& Johnson, M. K. (2007). Memory for emotional and neutral information: Gender and individual differences in emotional sensitivity. Memory, 15, 192-204.

Boelen, P. A., Stroebe, M. S., Schut, H. A. W., \& Zijerveld, A. M. (2006). Continuing relationships with the deceased: Disentangling bonds and grief. Death Studies, 30, 757-766.

Bonanno, G. A. (2001). Grief and emotion: A social-functional perspective. In M. S. Stroebe, R. O. Hansson, W. Stroebe, \& H. Schut (Eds.), Handbook of bereavement research (pp. 493-515). Washington, DC: American Psychological Association.

Bonanno, G. A., \& Kaltman, S. (1999). Toward an integrative perspective on bereavement. Psychological Bulletin, 125, 760-776.

Bonanno, G. A., \& Keltner, D. (1997). Facial expressions of emotion and the course of conjugal bereavement. Journal of Abnormal Psychology, 106, 126-137.

Bonanno, G. A., Keltner, D., Holen, A., \& Horowitz, M. J. (1995). When avoiding unpleasant emotion might not be such a bad thing: Verbalautonomic response dissociation and midlife conjugal bereavement. Journal of Personality and Social Psychology, 46, 975-989.

Bonanno, G. A., Wortman, C. B., Lehman, D. R., Tweed, R. G., Haring, M., Sonnega, J., et al. (2002). Resilience to loss and chronic grief: A prospective study from preloss to 18-months postloss. Journal of Personality and Social Psychology, 83, 1150-1164.

Bonanno, G. A., Znoj, H., Siddique, H. I., \& Horowitz, M. J. (1999). Verbal-autonomic dissociation and adaptation to midlife conjugal loss: A follow-up at 25 months. Cognitive Therapy and Research, 23, 605524.

Brown, P., \& Levinson, S. C. (1987). Politeness: Some universals in language usage. New York: Cambridge University Press.
Burnett, P., Middleton, W., Raphael, B., \& Martinek, N. (1997). Measuring core bereavement phenomena. Psychological Medicine, 27, 49-57.

Carnelley, K. B., Wortman, C. B., Bolger, N., \& Burke, C. T. (2006). The time course of grief reactions to spousal loss: Evidence from a national probability sample. Journal of Personality and Social Psychology, 91, 476-492.

Caserta, M. S., \& Lund, D. A. (1996). Beyond bereavement support group meetings: Exploring outside social contacts among the members. Death Studies, 20, 537-556.

Clark, L. F., Collins, J. E., \& Henry, S. M. (1994). Biasing effects of retrospective reports on current self-assessments. In N. Schwarz \& S. Sudman (Eds.), Autobiographical memory and the validity of retrospective reports (pp. 291-304). New York: Springer-Verlag.

Collins, N. L., \& Miller, L. C. (1994). Self-disclosure and liking: A meta-analytic review. Psychological Bulletin, 116, 457-475.

Compassionate Friends, Atlanta Area Chapters. (2009). The Compassionate Friends, Atlanta Area Chapters. Retrieved March 13, 2009, from http://www.tcfatlanta.org/

Conant, R. D. (1996). Memories of the death and life of a spouse: The role of images and sense of presence in grief. In D. Klass, P. R. Silverman, \& S. L. Nickman (Eds.), Continuing bonds: New understandings of grief (pp. 179-196). Washington, DC: Taylor \& Francis.

Currier, J. M., Holland, J. M., \& Neimeyer, R. A. (2006). Sense-making, grief, and the experience of violent loss: Toward a meditational model. Death Studies, 30, 403-428.

Davis, C. G., Lehman, D. R., Wortman, C. B., \& Silver, R. C. (1995). The undoing of traumatic life events. Personality and Social Psychology Bulletin, 21, 109-124.

Dyregrov, K. (2003-2004). Micro-sociological analysis of social support following traumatic bereavement: Unhelpful and avoidant responses from the community. Omega, 48, 23-44.

Field, N. P., \& Friedrichs, M. (2004). Continuing bonds in coping with the death of a husband. Death Studies, 28, 597-620.

Folkman, S. (2001). Revised coping theory and the process of bereavement. In M. S. Stroebe, R. O. Hansson, W. Stroebe, \& H. Schut (Eds.), Handbook of bereavement research (pp. 563-584). Washington, DC: American Psychological Association.

Freud, S. (1957). Mourning and melancholia. In J. Strachey (Ed. and Trans.), Standard edition of the complete psychological works of Sigmund Freud (Vol. 14, pp. 237-258). London: Hogarth. (Original work published 1917)

Gersie, A. (1991). Storymaking in bereavement: Dragons fight in the meadow. London: Kingsley.

Goffman, E. (1967). Interaction ritual: Essays on face-to-face interaction. Oxford, England: Aldine.

Guiaux, M., van Tilburg, T., \& van Groenou, M. B. (2007). Changes in contact and support exchange in personal networks after widowhood. Personal Relationships, 14, 457-473.

Hagman, G. (2001). Beyond decathexis: Toward a new psychoanalytic understanding and treatment of mourning. In R. A. Neimeyer (Ed.), Meaning reconstruction and the experience of loss (pp. 13-31). Washington, DC: American Psychological Association.

Harvey, J. H., Carlson, H. R., Huff, T. M., \& Green, M. A. (2001). Embracing their memory: The construction of accounts of loss and hope. In R. A. Neimeyer (Ed.), Meaning reconstruction and the experience of loss (pp. 231-244). Washington, DC: American Psychological Association.

Harvey, J. H., Orbuch, T. L., Weber, A. L., Merbach, N., \& Alt, R. (1992) House of pain and hope: Accounts of loss. Death Studies, 16, 99-124.

Hazen, M. A. (2003). Societal and workplace responses to perinatal loss: Disenfranchised grief or healing connection. Human Relations, 56, 147 166. 
Holmes, J. G. (2002). Interpersonal expectations as the building blocks of social cognition: An interdependence theory perspective. Personal Relationships, 9, 1-26.

Holtgraves, T. (1990). The language of self-disclosure. In H. Giles \& W. P. Robinson (Eds.), Handbook of language and social psychology (pp. 191-207). Oxford, England: Wiley.

James, W. (1950). The principles of psychology. New York: Dover. (Original work published 1890)

Janoff-Bulman, R. (1992). Shattered assumptions: Towards a new psychology of trauma. New York: Free Press.

Keltner, D., \& Bonanno, G. A. (1997). Facial expressions of emotion and the course of conjugal bereavement. Journal of Abnormal Psychology, 106, 126-137.

King, L. A., \& Noelle, S. S. (2005). Happy, mature, and gay: Intimacy, power, and difficult times in coming out stories. Journal of Research in Personality, 39, 278-298.

Klass, D. (1996). The deceased child in the psychic and social worlds of bereaved parents during the resolution of grief. In D. Klass, P. R. Silverman, \& S. L. Nickman (Eds.), Continuing bonds: New understandings of grief (pp. 199-216). Washington, DC: Taylor \& Francis.

Klass, D. (2001). Continuing bonds in the resolution of grief in Japan and North America. The American Behavioral Scientist, 44, 742-763.

Klass, D., \& Walter, T. (2001). Processes of grieving: How continuing bonds are continued. In M. S. Stroebe, R. O. Hansson, W. Stroebe, \& H. Schut (Eds.), Handbook of bereavement research (pp. 375-404). Washington, DC: American Psychological Association.

Kross, E., Ayduk, O., \& Mischel, W. (2005). When asking "why" does not hurt: Distinguishing rumination from reflective processing of negative emotions. Psychological Science, 16, 709-715.

Kubler-Ross, E., \& Kessler, D. (2005). On grief and grieving: Finding the meaning of grief through the five stages of loss. New York: Scribner.

Lalande, K. M., \& Bonanno, G. A. (2006). Culture and continuing bonds: A prospective comparison of bereavement in the United States and the People's Republic of China. Death Studies, 30, 303-324.

Laurenceau, J., Feldman Barrett, L., \& Pietromonaco, P. R. (1998). Intimacy as an interpersonal process: The importance of self-disclosure, partner disclosure, and perceived partner responsiveness in interpersonal exchanges. Journal of Personality and Social Psychology, 74, 12381251.

Leahy, J. M. (1992-1993). A comparison of depression in women bereaved of a spouse, child, or a parent. Omega: Journal of Death and Dying, 26, 207-217.

Lehman, D. R., Ellard, J. H., \& Wortman, C. B. (1986). Social support for the bereaved: Recipients' and providers' perspectives on what is helpful. Journal of Consulting and Clinical Psychology, 54, 438-446.

Luminet, O., Bouts, P., Delie, F., Manstead, A. S. R., \& Rime, B. (2000). Social sharing of emotion following exposure to a negatively valenced situation. Cognition \& Emotion, 14, 661-688.

Maercker, A., Bonanno, G. A., Znoj, H., \& Horowitz, M. J. (1998). Prediction of complicated grief by positive and negative themes in narratives. Journal of Clinical Psychology, 54, 1117-1136.

Maruna, S. (1997). Going straight: Desistance from crime and life narratives of reform. In A. Lieblich \& R. Josselson (Eds.), The narrative study of lives (pp. 59-93). Thousand Oaks, CA: Sage.

Marwit, S. J., \& Klass, D. (1996). Grief and the role of the inner representation of the deceased. In D. Klass, P. R. Silverman, \& S. L. Nickman (Eds.), Continuing bonds: New understandings of grief (pp. 297-309). Washington, DC: Taylor \& Francis.

Matthew Shepard Foundation. (2007). Foundation's Story. Retrieved August 23, 2007, from http://www.matthewshepard.org/site/PageServer? pagename $=$ found_Foundations_Story_Main_Page

McAdams, D. P., Reynolds, J., \& Lewis, M. (2001). When bad things turn good and good things turn bad: Sequences of redemption and contamination in life narrative and their relation to psychosocial adaptation in midlife adults and in students. Personality and Social Psychology Bulletin, 27, 474-485.

McLean, K. C., Pasupathi, M., \& Pals, J. L. (2007). Selves creating stories creating selves: A process model of self-development. Personality and Social Psychology Review, 11, 262-278.

Middleton, W., Raphael, B., Burnett, P., \& Martinek, N. (1998). A longitudinal study comparing bereavement phenomena in recently bereaved spouses, adult children, and parents. Australian and New Zealand Journal of Psychiatry, 32, 235-241.

Mikulincer, M., \& Nachshon, O. (1991). Attachment styles and patterns of self-disclosure. Journal of Personality and Social Psychology, 61, 321331.

Mikulincer, M., \& Shaver, P. R. (2003). The attachment behavioral system in adulthood: Activation, psychodynamics, and interpersonal processes. In M. P. Zanna (Ed.), Advances in experimental social psychology (Vol. 35, pp. 56-152). San Diego, CA: Academic.

Mikulincer, M., \& Shaver, P. R. (2007). Attachment in adulthood: Structure, dynamics, and change. New York: Guilford.

Miles, M. S., \& Crandall, E. K. B. (1983). The search for meaning and its potential for affecting growth in bereaved parents. Health Values, 7 , $19-23$.

Nadeau, J. W. (1998). Families making sense of death. Thousand Oaks, CA: Sage

Nadeau, J. W. (2001). Family construction of meaning. In R. A. Neimeyer (Ed.), Meaning reconstruction and the experience of loss (pp. 95-111). Washington, DC: American Psychological Association.

Neimeyer, R. A. (2001). Introduction: Meaning reconstruction and loss. In R. A. Neimeyer (Ed.), Meaning reconstruction and the experience of loss (pp. 1-12). Washington, DC: American Psychological Association.

Neimeyer, R. A., \& Levitt, H. (2001). Coping and coherence: A narrative perspective on resilience. In C. R. Snyder (Ed.), Coping with stress. Effective people and processes (pp. 47-67). New York: Oxford University Press.

Nolen-Hoeksema, S. (2001). Ruminative coping and adjustment to bereavment. In M. S. Stroebe, R. O. Hansson, W. Stroebe, \& H. Schut (Eds.), Handbook of bereavement research (pp. 545-562). Washington, DC: American Psychological Association.

Olsen, L. (2007). Ongoing thoughts on grief and loss. Retrieved August 25, 2007, from http://www.dubuque.k12.ia.us/parents/grief.htm

Ozyurek, A., \& Trabasso, T. (1997). Evaluation during the understanding of narratives. Discourse Processes, 23, 305-335.

Pals, J. L. (2006). Narrative identity processing of difficult life experiences: Pathways of personality development and positive self-transformation in adulthood. Journal of Personality, 74, 1079-1110.

Parkes, C. M. (2006). Love and loss: The roots of grief and its complications. New York: Routledge.

Pasupathi, M. (2001). The social construction of the personal past and its implications for adult development. Psychological Bulletin, 127, 651672.

Pasupathi, M. (2003). Emotion regulation during social remembering: Differences between emotions elicited during an event and emotions elicited when talking about it. Memory, 11, 151-163.

Pasupathi, M., \& Rich, B. (2005). Inattentive listening undermines selfverification in personal storytelling, Journal of Personality, 73, 10511086.

Pasupathi, M., Stallworth, L. M., \& Murdoch, K. (1998). How what we tell becomes what we know: Listener effects on speakers' long-term memory for events. Discourse Processes, 26, 1-25.

Pennebaker, J. W., \& Harber, K. D. (1993). A social stage model of coping: The Loma Prieta earthquake and the Persian Gulf war. Journal of Social Issues, 49, 125-145.

Pietila, M. (2002). Support groups: A psychological or social device for suicide bereavement? British Journal of Guidance \& Counseling, 30, 401-414. 
Reis, H. T., \& Shaver, P. (1988). Intimacy as an interpersonal process. In S. Duck, D. F. Hay, S. E. Hobfoll, W. Ickes, \& B. M. Montgomery (Eds.), Handbook of personal relationships: Theory, research and interventions (pp. 367-389). Oxford, England: Wiley.

Rime, B. (1995). Social and cognitive processing in emotion: A heuristic for psychopathology. In J. W. Pennebaker (Ed.), Emotion, disclosure, and health (pp. 271-291). Washington, DC: American Psychological Association.

Rime, B., Mesquita, B., Philippot, P., \& Boca, S. (1991). Beyond the emotional event: Six studies on the social sharing of emotion. Cognition and Emotion, 5, 435-465.

Rose, A. J., Carlson, W., \& Waller, E. M. (2007). Prospective associations of co-rumination with friendship and emotional adjustment: Considering the socioemotional trade-offs of co-rumination. Developmental Psychology, 43, 1019-1031.

Rosenblatt, P. C. (2000). Parent grief: Narratives of loss and relationship. Philadelphia: Brunner/Mazel.

Rubin, S., \& Malkinson, R. (2001). Parental response to child loss. In M. S. Stroebe, R. O. Hansson, W. Stroebe, \& H. Schut (Eds.), Handbook of bereavement research (pp. 219-240). Washington, DC: American Psychological Association.

Silverman, P. R., Nickman, S., \& Worden, J. W. (1992). Detachment revisited: The child's reconstruction of a dead parent. American Journal of Orthopsychiatry, 62, 494-503.

Singer, J. A., \& Blagov, P. (2004). The integrative function of narrative processing: Autobiographical memory, self-defining memories, and the life story of identity. In D. R. Beike, J. M. Lampinen, \& D. A. Behrend (Eds.), The self and memory (pp. 117-138). New York: Psychology.

Singer, J. A., \& Bluck, S. (2001). New perspectives on autobiographical memory: The integration of narrative processing and autobiographical reasoning. Review of General Psychology, 5, 91-99.

Singer, J. A., \& Moffitt, K. H. (1991-1992). An experimental investigation of specificity and generality in memory narratives. Imagination, Cognition and Personality, 11, 233-257.

Stroebe, M. S., \& Schut, H. (2001). Meaning making in the dual process model of coping with bereavement. In R. A. Neimeyer (Ed.), Meaning reconstruction and the experience of loss (pp. 55-73). Washington DC: American Psychological Association.

Stroebe, M. S., Schut, H., \& Stroebe, W. (2006). Who benefits from disclosure? Exploration of attachment style differences in the effects of expressing emotions. Clinical Psychology Review, 26, 66-85.

Stroebe, M. S., \& Stroebe, W. (1991). Does grief work, work? Journal of Consulting and Clinical Psychology, 59, 479-482.

Stroebe, M. S., \& Stroebe, W., Schut, H., Zech, E., \& van den Bout, J. (2002). Does disclosure of emotions facilitate recovery from bereavement? Evidence from two prospective studies. Journal of Consulting Psychology, 70, 169-178.

Stroebe, W., Schut, H., \& Stroebe, M. S. (2005). Grief work, disclosure and counseling: Do they help the bereaved? Clinical Psychology Review, 25, 395-414.
Stroebe, W., Zech, E., Stroebe, M. S., \& Abakoumkin, G. (2005). Does social support help in bereavement? Journal of Social and Clinical Psychology, 24, 1030-1050.

Thorne, A., Korobov, N., \& Morgan, E. M. (2007). Channeling identity: A study of storytelling in conversations between introverted and extraverted friends. Journal of Research in Personality, 41, 1008-1031.

Thorne, A., \& McLean, K. C. (2003). Telling traumatic events in adolescence: A study of master narrative positioning. In R. Fivush \& C. Haden (Eds.), Connecting culture and memory: The development of an autobiographical self (pp. 169-185). Mahwah, NJ: Erlbaum.

Tracy, K. (1990). The many faces of facework. In H. Giles \& W. P. Robinson (Eds.), Handbook of language and social psychology (pp. 209-226). Oxford, England: Wiley.

Walter, T. (1996). A new model of grief: Bereavement and biography. Mortality, 1, 7-25.

Webster, J. D. (1993). Construction and validation of the Reminiscence Functions Scale. Journals of Gerontology, 48, 256-262.

Webster, J. D. (2003). The reminiscence circumplex and autobiographical memory functions. Memory, 11, 203-215.

Weinberger, D. A. (1998). Defenses, personality structure, and development: Integrating psychodynamic theory into a typological approach to personality. Journal of Personality 19, 1061-1080.

Wheeler, I. (2001). Parental bereavement: The crisis of meaning. Death Studies, 25, 51-66.

Williams, J. M. G. (1996). Depression and the specificity of autobiographical memory. In D. C. Rubin (Ed.), Remembering our past: Studies in autobiographical memory (pp. 244-267). New York: Cambridge University Press.

Wilson, A. E., \& Ross, M. (2003). The identity function of autobiographical memory: Time is on our side. Memory, 11, 137-149.

Wolfelt, A. D. (1998). Healing your grieving heart: 100 practical ideas. Fort Collins, CO: Companion.

Worden, J. W. (2002). Grief counseling and grief therapy: A handbook for the mental health practitioner (3rd ed.). New York: Springer.

Wortman, C. B., \& Boerner, K. (2007). Beyond the myths of coping with loss: Prevailing assumptions versus scientific evidence. In H. Friedman \& R. Silver (Eds.), Foundations of health psychology (pp. 285-324). New York: Oxford University Press.

Zech, E., Rime, B., \& Nils, F. (2004). Social sharing of emotion, emotional recovery, and interpersonal aspects. In P. Philippot \& R. S. Feldman (Eds.), The regulation of emotion (pp. 157-185). New York: Routledge.

Zech, E., Rime, B., \& Pennebaker, J. W. (2007). The effects of emotional disclosure during bereavement. In M. Hewstone, H. A. W. Schut, J. B. F. De Wit, K. Van Den Bos, \& M. S. Stroebe (Eds.), The scope of social psychology: Theory and applications (pp. 277-292). New York: Psychology.

Received December 12, 2008

Revision received February 12, 2009

Accepted February 23, 2009 